EXTENDED REPORT

\title{
Cost effectiveness of etanercept (Enbrel) in combination with methotrexate in the treatment of active rheumatoid arthritis based on the TEMPO trial
}

\author{
G Kobelt, P Lindgren, A Singh, L Klareskog
}

See end of article for authors' affiliations

Correspondence to: Dr G Kobelt, European Health Economics SAS, 492 chemin des Laurens, F-06530 Spéracèdes, France; gisela.kobelt@ he-europe.com

Accepted 7 February 2005 Published Online First 11 February 2005
Objective: To estimate the cost effectiveness of combination treatment with etanercept plus methotrexate in comparison with monotherapies in patients with active rheumatoid arthritis (RA) using a new model that incorporates both functional status and disease activity.

Methods: Effectiveness data were based on a 2 year trial in 682 patients with active RA (TEMPO). Data on resource consumption and utility related to function and disease activity were obtained from a survey of 616 patients in Sweden. A Markov model was constructed with five states according to functional status (Health Assessment Questionnaire (HAQ)) subdivided into high and low disease activity. The cost for each quality adjusted life year (QALY) gained was estimated by Monte Carlo simulation.

Results: Disease activity had a highly significant effect on utilities, independently of HAQ. For resource consumption, only $\mathrm{HAQ}$ was a significant predictor, with the exception of sick leave. Compared with methotrexate alone, etanercept plus methotrexate over 2 years increased total costs by $€ 14221$ and led to a QALY gain of 0.38 . When treatment was continued for 10 years, incremental costs were $€ 42148$ for a QALY gain of 0.91 . The cost per QALY gained was $€ 37331$ and $€ 46494$, respectively. The probability that the cost effectiveness ratio is below a threshold of $€ 50000 / Q A L Y$ is $88 \%$.

Conclusion: Incorporating the influence of disease activity into this new model allows better assessment of the effects of anti-tumour necrosis factor treatment on patients' general wellbeing. In this analysis, the cost per QALY gained with combination treatment with etanercept plus methotrexate compared with methotrexate alone falls within the acceptable range.
$\mathrm{T}$ he cost effectiveness of treatments that have the potential to change the "natural history" of a chronic progressive disease has to be evaluated over the long term. This implies the use of models that allow varying the assumptions about treatment continuation and effects in the longer term and that provide estimates of the uncertainty surrounding the results, including those of the clinical trials. We have earlier proposed a general approach to modelling cost and outcomes and to assessing cost effectiveness in chronic progressive diseases. ${ }^{1}$ The approach involves using disease models based on epidemiological data where costs and quality of life (utility) are related to a measure of disease severity and progression. In the models for rheumatoid arthritis (RA), ${ }^{2}{ }^{3}$ we defined disease severity based on functional status measured by the Health Assessment Questionnaire (HAQ) ${ }^{4}$ and expressed outcome as quality adjusted life years (QALYs). ${ }^{5}$ Cost effectiveness estimates are based on the concept that with treatment, patients will not progress to the next level(s) of disease severity, or will take longer to progress, thus avoiding or delaying the high costs and low utility associated with more severe disease. ${ }^{67}$

The effect of the new biological drugs on disease activity has increased the focus on the role of disease activity in the development of functional disability. In our earlier models we had assumed that the effect of disease activity was expressed through its effect on functional status. However, when analysing observational data on patients treated with tumour necrosis factor inhibitors, we found that disease activity had a significant impact on utility, independently from HAQ. ${ }^{8}$ We therefore suggested that at a given level of functional status, much of the variability of utility was explained by disease activity, and we used a survey of 616 patients in southern Sweden to investigate further the effect of disease activity on utility and costs. The results were incorporated into a new cost effectiveness model (data submitted).

The objective of the present study was to use this new model in the analysis of a controlled trial where there is a need to take both disease activity and function into account when estimating cost effectiveness.

\section{PATIENTS AND METHODS}

\section{Effectiveness data}

The analysis is based on a double blind, randomised clinical trial in 682 patients (Trial of Etanercept and Methotrexate with Radiographic Patient Outcomes, TEMPO). ${ }^{9}$ In this trial patients with active disease for whom previous disease modifying antirheumatic drugs (DMARDs) other than methotrexate had failed were randomised to receive etanercept $25 \mathrm{mg}$ (subcutaneously twice a week), methotrexate (up to $20 \mathrm{mg}$ every week), or etanercept plus methotrexate for a period of 2 years. Patients previously exposed to methotrexate were included provided they were deemed to be appropriate candidates for methotrexate treatment at the time of enrolment in the study.

All randomised patients who had received a first treatment were included in the cost effectiveness analysis (intention to treat analysis, $n=682$ ). Table 1 shows the demographics of the sample used in this analysis.

Abbreviations: DAS28, 28 joint count Disease Activity Score; DMARDs, disease modifying antirheumatic drugs; EQ-5D, EuroQol five item questionnaire for measuring utility; $\mathrm{HAQ}$, Health Assessment Questionnaire; QALY, quality adjusted life year; RA, rheumatoid arthritis; TEMPO, Trial of Etanercept and Methotrexate with Radiographic Patient Outcomes; VAS, visual analogue scale 


\begin{tabular}{|c|c|c|c|}
\hline & $\begin{array}{l}\text { Etanercept/ } \\
\text { methotrexate } \\
\text { Mean (SD) }\end{array}$ & $\begin{array}{l}\text { Etanercept } \\
\text { Mean (SD) }\end{array}$ & $\begin{array}{l}\text { Methotrexate } \\
\text { Mean (SD) }\end{array}$ \\
\hline \multicolumn{4}{|l|}{ Baseline } \\
\hline Number & & 223 & 228 \\
\hline Age (years) & $53.0(12.8)$ & 53.2 (13.8) & $52.5(12.4)$ \\
\hline $\begin{array}{l}\text { Disease duration } \\
\text { (years) }\end{array}$ & $6.8(5.5)$ & $6.3(5.1)$ & $6.8(5.4)$ \\
\hline $\mathrm{HAQ}$ & $1.8(0.6)$ & $1.8(0.7)$ & $1.7(0.7)$ \\
\hline DAS28 & $6.8(1.0)$ & $6.9(0.9)$ & $6.7(1.0)$ \\
\hline \multicolumn{4}{|l|}{1 Year } \\
\hline Number* & 193 & 170 & 159 \\
\hline HAQ (year 1) & $0.7(0.7)$ & $0.8(0.7)$ & $0.9(0.8)$ \\
\hline DAS28 (year 1) & $3.1(1.4)$ & $3.7(1.3)$ & $3.9(1.5)$ \\
\hline \multicolumn{4}{|l|}{2 Years } \\
\hline Number* & & & \\
\hline $\mathrm{HAQ}$ (year 2) & $0.7(0.7)$ & $0.8(0.7)$ & $0.9(0.8)$ \\
\hline DAS28 (year 2) & $2.8(1.3)$ & $3.4(1.3)$ & $3.6(1.5)$ \\
\hline \multicolumn{4}{|c|}{$\begin{array}{l}\text { Results are shown as mean (SD). } \\
\text { "For the purpose of the model, patients who withdrew from treatment are } \\
\text { assumed to have returned to their baseline scores. } \\
\text { HAQ, Health Assessment Questionnaire; DAS28, } 28 \text { joint count Disease } \\
\text { Activity Score. }\end{array}$} \\
\hline
\end{tabular}

\section{The model}

Development of the disease is represented using a Markov mode ${ }^{10}$ with five main functional states and cut off points at HAQ 0.6, 1.1, 1.6, 2.1. Each state is further separated into two substates representing high and low disease activity. All resulting 10 states are further subdivided according to those receiving study treatment or not. Changes in disease status are modelled as transitions between the states at intervals of 1 year (cycles). Costs and utility are assigned to each of the 20 states and the model estimates expected costs and QALYs for defined cohorts of patients over given periods of time.

\section{Disease progression}

Transition probabilities for the first 2 years are calculated based on the observed transitions in the clinical trial for patients with a HAQ measurement at both the start and the end of each year. Transition probabilities beyond the trial are based on the average reported annual progression of HAQ (0.03). Scott and colleagues have published a comprehensive review of studies investigating changes in HAQ and found a mean annual increase of $0.031 .^{11}$

\section{Mortality}

A number of studies have shown increased mortality in patients with RA, but reports have not been consistent. Standardised mortality ratios have been reported to range from 1.16 to $3.0,{ }^{12}{ }^{13}$ and a link with disease activity has been shown. ${ }^{14}{ }^{15}$ Recent studies in North America and the UK recorded standardised mortality ratios of 1.32 and $3.08,{ }^{12}{ }^{15-17}$ whereas studies in Norway and Sweden reported 1.57 and 2.0, respectively. ${ }^{18}{ }^{19}$ Studies in early RA, on the other hand, including the Lund cohort study, did not show evidence of any increased mortality during the first 10 years of follow up..$^{21}$

The model therefore includes normal mortality adjusted for age and sex in the two early HAQ states $(<1.1)$, whereas in the three more advanced states, we adjust normal mortality with a relative risk of 1.3 and 2.0 in states with low and high disease activity, respectively.

\section{Disease activity}

In clinical trials, disease activity is currently measured with the Disease Activity Score (DAS) or 28 joint count DAS
(DAS28), and low disease activity has been defined as a DAS28 score of $\leqslant 3.2 .^{22}$ However, DAS28 is a recent scoring method and has not been included in cohort studies or registries in the past. Also, it is difficult to assess DAS28 in population surveys, as it requires clinical and laboratory measurements. As an alternative, the patient global visual analogue scale (global VAS) has been used when assessing disease activity and severity-for example, in registries, with high disease activity being defined as a VAS of $\geqslant 40 .{ }^{23}$ We have confirmed this cut off point by correlating the patient global VAS with the DAS28 in the TEMPO trial and found that a DAS28 of 3.2 corresponds to a score of 41 on the global VAS.

\section{Utility and resource utilisation survey}

In 1997 a survey in 1016 patients with confirmed RA, representing an estimated $90-95 \%$ of patients in the area, was carried out by the department of rheumatology at Malmö University Hospital. ${ }^{24}$ In 2002 a follow up survey answered by 616 patients included a questionnaire on resource consumption and work capacity, as well as the EQ-5D (EuroQol). ${ }^{25} 26$ The mean age of the patients was 64.5 years, $74 \%$ were female, and the mean disease duration was 16.7 years.

\section{Utilities}

Utility scores were derived from the five dimensional health state classification of the EQ-5D and related to both HAQ scores and disease activity using multiple regression.

The TEMPO trial included the EuroQol VAS, and we investigated the differences in scores between the treatment groups using regression analysis, controlling for functional status (HAQ) and disease activity.

\section{Resource utilisation}

Direct resource utilisation included all healthcare and community services as well as investments, devices, transportation, and informal help. Indirect costs included early retirement due to RA, long and short term sick leave, loss of leisure time. Early retirement due to RA has been shown to be one of the most important cost drivers in economic evaluations in RA. To increase the sample size and to account for potential regional variations we combined the Malmö data with early retirement data for 1810 patients in the Stockholm area, currently followed up in the National Swedish RA registry. ${ }^{27}$

\section{Unit costs and valuation}

Costs for healthcare and community services were obtained from the county councils of southern Sweden ${ }^{28}$ and the national price list for drugs. ${ }^{29}$ The annual cost of etanercept and methotrexate in Sweden is $€ 16000$ and $€ 78$, respectively, excluding monitoring costs. Mean annual labour cost by sex (mean salary plus employers' costs) for 2001 was available from the statistical yearbook $2003^{30}$ and inflated to 2004. Informal help and care was valued as leisure time, using the estimated net income after tax in Sweden (35\% of full labour cost).

The analysis is performed from the societal perspective and includes all costs, regardless of the payer. The full patient dataset of costs and utilities is incorporated into the model and bootstrapping is used for the simulations. Costs and effects are discounted by $3 \%$.

\section{Cost effectiveness simulations}

Transitions for all patients in the clinical trial are used directly during the first 2 years and the model then extrapolates to 10 (5) years. All patients in the trial had high disease activity at baseline according to our definition. We first present an analysis of the trial effect only, without 
Table 2 Utilities by functional capacity and disease activity (Malmö survey)

\begin{tabular}{|c|c|c|c|c|c|}
\hline \multirow{2}{*}{$\begin{array}{l}\text { Functional states } \\
\text { (HAQ) }\end{array}$} & \multirow[b]{2}{*}{ Number* } & \multicolumn{3}{|c|}{ Utility scores (SD) -EQ-5D } & \multirow{2}{*}{$\begin{array}{l}\text { Proportion VAS } \\
\geqslant 40(\%)\end{array}$} \\
\hline & & All & Global VAS $<\mathbf{4 0}$ & Global VAS $\geqslant 40$ & \\
\hline$<0.6$ & 157 & $0.768(0.117)$ & $0.780(0.120)$ & $0.709(0.078)$ & 16.7 \\
\hline 0.6 to $<1.1$ & 112 & $0.645(0.200)$ & $0.704(0.154)$ & $0.568(0.227)$ & 43.8 \\
\hline 1.1 to $<1.6$ & 118 & $0.539(0.247)$ & $0.676(0.104)$ & $0.441(0.273)$ & 58.6 \\
\hline 1.6 to $<2.1$ & 64 & $0.488(0.255)$ & $0.562(0.224)$ & $0.446(0.264)$ & 64.1 \\
\hline$\geqslant 2.1 \dagger$ & 68 & $0.239(0.265)$ & $0.408(0.257)$ & $0.213(0.265)$ & 86.8 \\
\hline
\end{tabular}

Results are shown as mean (SD).

*Patients with complete values on EQ-5D and patient global VAS; tnegative scores set to zero; using negative scores, mean utility $=0.162(0.336)$.

$\mathrm{HAQ}$, Health Assessment Questionnaire; Global VAS, visual analogue scale of disease severity and activity.

any assumptions about treatment continuation. Thus, at the end of the trial, patients stop treatment and follow the annual disease progression with standard treatment $(+0.03$ HAQ). Patients in the etanercept and etanercept plus methotrexate groups revert to their baseline HAQ and DAS28 scores over the next cycle, except if scores had deteriorated during the trial. In the latter case, patients remain at the level reached at the end of the trial. The same logic is applied to patients withdrawing from treatment during the trial. Patients in the methotrexate group in states 3 to 5 revert to a slightly higher HAQ score than at baseline $(+0.005$ /year $)$. The rationale for this is the difference in radiological progression in the groups. Sharp scores remained stable and even slightly improved in patients treated with etanercept or with etanercept plus methotrexate, but progressed by 2.8 points a year in patients treated with methotrexate. This corresponds to approximately $35 \%$ of the mean annual progression of $1.6-1.9 \%$ of maximum possible damage estimated by Scott and colleagues. ${ }^{11}$ Using a correlation of 0.5 between Sharp and HAQ scores after 5 years of disease duration calculated by the same authors, we estimated the effect on the annual HAQ progression to be $15-20 \%$ in patients with $\geqslant 5$ years' disease duration and an HAQ score $>1.1$.

We also present an analysis with treatment continuation for the full 5 or 10 years, using the second year of the trial to make assumptions. HAQ scores during this year were stable for patients receiving treatment, and the withdrawal rates were $22 \%, 16 \%$, and $13 \%$ in the methotrexate, etanercept, and etanercept plus methotrexate arms, respectively. We thus used the group-specific transitions from the second year of the trial for the extrapolation, and assumed that dropouts accounted for treatment failure due to lack of efficacy or adverse events.

The uncertainty in the cost effectiveness results is dealt with by using acceptability curves. ${ }^{31}{ }^{32}$ In these calculations, a threshold for the willingness to pay for a QALY is defined and the probability estimated of the cost per QALY gained falling below this threshold, using the full range of patient level

\begin{tabular}{lllll}
$\begin{array}{l}\text { Table } 3 \\
\text { trial }\end{array}$ & EuroQol VAS scores by treatment in the TEMPO \\
\hline \multicolumn{5}{c}{ Mean EuroQol VAS scores* } \\
\cline { 2 - 5 } $\begin{array}{l}\text { Functional } \\
\text { states }\end{array}$ & \multicolumn{3}{c}{ All patients } & Etanercept/ \\
& methotrexate Etanercept & Methotrexate \\
\hline$<0.6$ & 76.51 & 79.12 & 76.42 & 72.88 \\
0.6 to $<1.1$ & 67.73 & 71.22 & 66.89 & 64.02 \\
1.1 to $<1.6$ & 63.57 & 64.59 & 67.04 & 58.77 \\
1.6 to $<2.1$ & 59.17 & 61.41 & 59.51 & 57.10 \\
$\geqslant 2.1$ & 51.81 & 52.92 & 55.96 & 47.50 \\
\hline
\end{tabular}

*EuroQol VAS scores are calculated with regression analysis using all measurements in the trial at all follow up visits. data. Acceptability curves are created with Monte Carlo simulation. We used bootstrapping to estimate the uncertainty around the model inputs (transition probabilities, costs, utilities). ${ }^{33}$ In each Monte Carlo simulation, 1 of 1000 bootstrap estimates for each measure is drawn at random and used.

\section{RESULTS}

\section{Utilities}

Utility scores correlated significantly with both HAQ and disease activity $(\mathrm{p}<0.001)$. Patients with high disease activity had consistently lower utilities at the same HAQ level (table 2).

The EuroQol VAS scores in TEMPO indicated similar results, but as expected, the VAS shows a substantial ceiling and floor effect. However, across all functional states, patients in the TEMPO trial treated with etanercept had consistently higher scores, as shown in table 3. The difference was estimated by regression analysis, and utility scores were subsequently adjusted by 0.04 for patients in the etanercept plus methotrexate group, and by 0.02 in the etanercept group, compared with methotrexate alone.

\section{Costs}

Table 4 shows that total costs correlated significantly with HAQ but not with disease activity (when controlling for HAQ), although a trend was found. An exception to this was short and medium term sick leave ( $<12$ months), which correlated significantly with disease activity, but not with HAQ. When patients aged 65 years or less were included, costs for sick leave were estimated at $€ 2262$ and $€ 4686$ for patients with low and high disease activity, respectively. The effect of age and disease duration on costs was not significant when HAQ was included.

\section{Modelling results}

Table 5 presents the base case with 2 years' treatment. Excluding study treatment, mean direct costs for each patient are $€ 49353$, $€ 52377$, and $€ 54531$ in the etanercept plus methotrexate, etanercept, and methotrexate groups, respectively. Patient-borne costs were €8715, €9127, and €9331, while indirect costs were $€ 102224$, $€ 105835$, and $€ 108$ 059. Of these latter, sick leave amounted to $€ 30798$, $€ 31443$, and $€ 31709$. Thus, the cost offset with etanercept plus methotrexate compared with methotrexate alone was $€ 11013$, compensating in part for the treatment cost of $€ 25339$.

The number of QALYs over 10 years was estimated at 3.46, 3.23, and 3.08 in the three groups respectively, leading to a QALY gain with etanercept plus methotrexate compared with methotrexate alone of 0.38 . This would be equivalent to 4 months in full health.

In the base case, the incremental cost per QALY for etanercept plus methotrexate compared with methotrexate 
Table 4 Costs by functional capacity, 2004

\begin{tabular}{|c|c|c|c|c|c|c|}
\hline \multirow[b]{2}{*}{ Functional states } & \multirow[b]{2}{*}{ Number } & \multicolumn{5}{|c|}{ Mean (SD) costs, $2004(€)$} \\
\hline & & Direct costs & Patient costs & Work absence & Retirement costs* & Total costs \\
\hline$<0.6$ & 180 & $773(1112)$ & $276(1107)$ & $1311(4714)$ & $1882(7207)$ & 4242 \\
\hline 0.6 to $<1.1$ & 132 & 1590 (4178) & $421(886)$ & 2629 (6809) & $4310(9920)$ & 8950 \\
\hline 1.1 to $<1.6$ & 126 & 2456 (4908) & $760(1614)$ & 2496 (6697) & $6467(11638)$ & 12179 \\
\hline 1.6 to $<2.1$ & 81 & $3496(6459)$ & 1388 (2946) & $1142(3796)$ & 7468 (11830) & 13494 \\
\hline$\geqslant 2.1$ & 97 & $8890(15191)$ & 1333 (2257) & $470(3274)$ & $7902(12396)$ & 18595 \\
\hline
\end{tabular}

alone was estimated to be $€ 37331$. When patients continue treatment beyond the trial, cost effectiveness ratios increased from $€ 37331$ to $€ 46494$ per QALY gained for up to 10 years and to $€ 47316$ per QALY gained for 5 years' treatment (table 6).

\section{Sensitivity analyses}

Our results are most sensitive to assumptions about the cost of the treatment and the difference in utility between the treatment groups (table 7). Utility, being highly sensitive to changes in HAQ or in disease activity, is an expression of treatment effectiveness, and results are thus sensitive to changes in effectiveness. Faster disease progression leads to lower cost effectiveness ratios, as costs in patients receiving standard treatment increase more rapidly. A higher dropout rate decreases treatment costs, but increases overall costs. Higher costs for patients with high disease activity have a very limited effect, as has RA-specific mortality. Cost effectiveness ratios are somewhat lower for patients of working age, as the potential for cost offsets is larger.

Using a threshold value of $€ 50000$ for the willingness to pay for a QALY gained, the probability that 2 years' treatment with etanercept plus methotrexate is acceptable is $88 \%$. With 10 years' treatment, the probability is $71 \%$. For a threshold of $€ 82000$, the probability is $99 \%$ and $98 \%$, respectively (fig 1).

\section{DISCUSSION}

When new data (for example clinical results in different patient populations, over different time periods, compared with different alternatives) become available, it is necessary to re-evaluate earlier cost effectiveness estimates in order to base decisions on the best available data. The TEMPO trial demonstrated benefits of combination therapy with etanercept plus methotrexate over either agent alone ${ }^{9}$ among patients deemed appropriate for methotrexate (up to $20 \mathrm{mg}$ ) treatment at the time of enrolment. As methotrexate is the standard first line disease modifying agent, this design

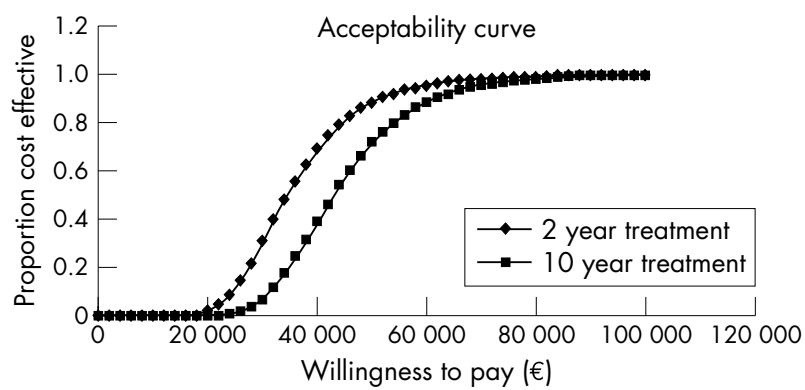

Figure 1 Uncertainty in the cost effectiveness estimates (acceptability curves) of a 2 or 10 year intervention with etanercept plus methotrexate in patients with active RA over 10 years. Acceptability curves are generated by Monte Carlo simulation, using individually drawn bootstrap estimates (1000 in this case) from the entire distribution of costs and utilities in the different Markov states. Different levels of willingness to pay for a QALY are defined and the probabilities of the cost effectiveness ratio falling below these different thresholds estimated. The probability that a 2 year treatment with etanercept plus methotrexate in a cohort of patients such as that included in the TEMPO trial is acceptable when the willingness to pay for a QALY is $€ 50000$ is $88 \%$. For a 10 year treatment, the probability is $71 \%$. For a threshold value of $€ 82000$, the probability is 99 and $98 \%$, respectively.

allows a fair comparison of clinical benefits of the three treatment regimens in a clinically relevant context and warrants economic evaluation.

Further, when new insights into disease processes are gained, and new or different disease measures are used, these must be incorporated into economic models. Economic evaluations in RA have been based on disease progression expressed by the HAQ, which has been found to correlate with both costs and utilities. However, our new data show that disease activity has an additional and highly significant effect on utilities.

The observational dataset underlying the model did not include the DAS28. We therefore used the patient global VAS

Table 5 Cost per QALY gained, treatment during the clinical trial only, 2004

\begin{tabular}{|c|c|c|c|c|c|}
\hline & Costs $(€)$ & $\begin{array}{l}\text { Difference } \\
\text { (from MTX) }\end{array}$ & $\begin{array}{l}\text { Effects } \\
\text { (QALYs) }\end{array}$ & $\begin{array}{l}\text { Difference } \\
\text { (from MTX) }\end{array}$ & $\begin{array}{l}\text { Cost per QALY } \\
\text { gained ( } v \text { MTX) }\end{array}$ \\
\hline \multicolumn{6}{|c|}{ Treatment for 2 years, extrapolation to 10 years } \\
\hline Methotrexate & 162695 & & 3.08 & & \multirow{3}{*}{$\begin{array}{l}\text { Dominated* } \\
37331\end{array}$} \\
\hline Etanercept & 181271 & 18577 & 3.23 & 0.15 & \\
\hline Etanercept/methotrexate & 176915 & 14221 & 3.46 & 0.38 & \\
\hline \multicolumn{6}{|c|}{ Treatment for 2 years, extrapolation to 5 years } \\
\hline Methotrexate & 84289 & & 1.86 & & \multirow{3}{*}{$\begin{array}{l}\text { Dominated* } \\
54548\end{array}$} \\
\hline Etanercept & 104060 & 19771 & 1.99 & 0.13 & \\
\hline Etanercept/methotrexate & 101286 & 16997 & 2.17 & 0.31 & \\
\hline \multicolumn{6}{|c|}{$\begin{array}{l}\text { *From an economic point of view, in this patient population etanercept alone is dominated by the combination of } \\
\text { etanercept plus methotrexate, which has both lower costs and higher utility. This does not indicate, however, that } \\
\text { from a clinical point of view, monotherapy should not be considered. } \\
1 \text { euro }=9.20 \text { Swedish kronor. }\end{array}$} \\
\hline
\end{tabular}


Table 6 Cost per QALY gained, treatment continuation beyond the trial, 2004

\begin{tabular}{|c|c|c|c|c|c|}
\hline & Costs $(€)$ & $\begin{array}{l}\text { Difference } \\
\text { (from MTX) }\end{array}$ & $\begin{array}{l}\text { Effects } \\
\text { (QALYs) }\end{array}$ & $\begin{array}{l}\text { Difference } \\
\text { (from MTX) }\end{array}$ & $\begin{array}{l}\text { Cost per QALY } \\
\text { gained ( } v \text { MTX) }\end{array}$ \\
\hline \multicolumn{6}{|l|}{ Treatment for 10 years } \\
\hline Methotrexate & 149943 & & 3.43 & & \\
\hline Etanercept/methotrexate & 192091 & 42148 & 4.34 & 0.91 & 46494 \\
\hline \multicolumn{6}{|c|}{ Treatment for 5 years, extrapolation to 10 years } \\
\hline Methotrexate & 154262 & & 3.31 & & \\
\hline Etanercept/methotrexate & 185030 & 30768 & 3.96 & 0.65 & 47316 \\
\hline
\end{tabular}

in the study as a measure of disease activity. This has been done by other authors, ${ }^{23}$ and we provided further justification for this by correlating the DAS2 8 and the global VAS in the TEMPO trial.

Contrary to its significant effect on utilities, disease activity was not significantly related to costs (except for sick leave). This might be explained in a number of ways-firstly, owing to the size of the sample. When patients are distributed into the 10 disease states in the model, the number of patients in the individual cells is small. Secondly, some of the major drivers of costs, such as surgical interventions and the loss of work capacity, are "long term" costs and thus are strongly related to function rather than to inflammation. Lastly, it is possible that patients with RA are followed up rather regularly, as almost all of them are treated with DMARDs. Inflammatory episodes may thus be taken care of during routine management. When testing the effect of a $20 \%$ increase in costs in states with high disease activity, the impact on the cost effectiveness results was very limited, owing to the much stronger impact of function.

Our analysis does not include any costs for adverse drug reactions, as these were similar in the three groups of the TEMPO trial. Cost effectiveness analyses are driven by differences in effects and resource utilisation between the comparators, and it is therefore not necessary to estimate costs of side effects in this case.

The trial did not follow up patients who withdrew from treatment, and to perform an intention to treat analysis we had to make certain assumptions. In the model, patients withdrawing from treatment return to their baseline values over the next cycle (except if their scores have deteriorated) and receive standard treatment with a mixture of DMARDs as in the Malmö survey. This latter is a conservative assumption, as it is probable that this type of patient will receive one of the other biological treatments, if the study treatment fails. Thus, costs incurred by patients after withdrawal may be underestimated in our analysis.

The clinical trial showed a difference in radiological progression in the three groups, but currently radiological scores are not incorporated as a separate measure into our model owing to a lack of adequate datasets. We have therefore conservatively assumed that the effect is included in the HAQ scores while patients are receiving treatment. However, when patients withdraw from treatment and return to their baseline HAQ score, this difference should be accounted for. As radiological damage affects HAQ mostly in advanced disease, ${ }^{11}$ we applied a small HAQ correction to the baseline scores of patients with an HAQ above 1.1 and who had 5 or more years of disease duration.

In the model, effectiveness is maintained for as long as the patient continues to receive treatment. This is supported by the second year in the trial, but even more so by longer term follow up studies with etanercept, where it was shown that effectiveness was maintained in patients continuing treatment for over 7 years. ${ }^{34-36}$ However, a final answer will have to come from long term observational studies in clinical practice.

Cost effectiveness estimates are presented for 10 years. Extrapolating to 10 years based on a 2 year trial may be questionable, and we therefore also present results for 5 years, where assumptions have a more limited effect. Nevertheless, in chronic progressive diseases, 5 years-and even 10 years - is a limited time. The benefits of modifying the course of the disease will be evident only in the long term, as high costs and low utility of severe disability are avoided or postponed. A question of particular interest in this respect is

Table 7 Cost $(€)$ per QALY gained with etanercept plus methotrexate compared with methotrexate alone, sensitivity analyses, 2004

\begin{tabular}{llll}
\hline Base case & $\begin{array}{l}\text { Incremental } \\
\text { cost (€) }\end{array}$ & $\begin{array}{l}\text { Incremental } \\
\text { effect }\end{array}$ & $\begin{array}{l}\text { Cost per QALY } \\
\text { gained (v MTX) }\end{array}$ \\
\hline 2 Year treatment, extrapolation to 10 years & 20056 & 0.38 & 52649 \\
Direct costs only & 14533 & 0.37 & 38726 \\
Annual HAQ progression 0 & 14094 & 0.38 & 36691 \\
Annual HAQ progression 0.06 & 14130 & 0.38 & 36779 \\
Annual HAQ progression 0.09 & 13566 & 0.38 & 35700 \\
Costs for patients with high disease activity 20\% higher & 14221 & 0.34 & 41667 \\
Utility difference between the treatment groups reduced by & & & 36655 \\
50\% & 13886 & 0.38 & 25514 \\
No effect of RA on mortality & 9719 & 0.38 & 35700 \\
Median European price for etanercept & 20194 & 0.38 & 33176 \\
Starting age 65 years & 13733 & 0.41 & 29947 \\
Discounting 0\% & 14458 & 0.36 & \\
Discounting 5\% & & & \\
10 Year treatment & 32711 & 0.79 & \\
Higher dropout after trial (double the risk) & & & \\
\hline 1 euro = 9.20 Swedish kronor. & & &
\end{tabular}


therefore whether early treatment with expensive but effective treatments is cost effective. The number of patients with recent disease onset in TEMPO is limited and does not allow such an analysis.

The estimates in this model are very stable, owing to the large datasets used, and only the treatment cost and the change in utility affect cost effectiveness ratios significantly. Under all assumptions presented, the mean ratios fall within the generally accepted range of willingness to pay for a QALY. Although no official level has been defined, it is generally assumed that a cost per QALY below $€ 50000$ is acceptable in Europe, and threshold values for Sweden have been estimated at around $€ 60000 .^{37}$ The National Institute for Clinical Excellence in the United Kingdom appears to use a threshold of around $€ 45000,{ }^{38}$ whereas values as high as $€ 100000$ are used in the United States. ${ }^{39}$ More recently, a value of three times the gross domestic product per head has been suggested as a threshold, which would result in approximately $€ 82000$ for Sweden. When testing the uncertainty in our results using these thresholds, the acceptability curves indicate that $88-99 \%$ of the cost effectiveness estimates fall within these ranges. Thus, combination treatment with etanercept plus methotrexate appears cost effective compared with methotrexate alone in patients such as those included in the TEMPO trial.

This is to our knowledge the first economic study that incorporates the effect of disease activity, in addition to functional status, making the model better adapted to estimating the cost effectiveness of treatment with a marked effect on disease activity. However, long term disease changes are based on changing progression, as noted in the past, and it will take several years to verify such changes.

\section{ACKNOWLEDGEMENTS}

We are grateful to Lennart Jacobsson, MD PhD, and Ylva Lindroth, MD PhD (Malmö University Hospital), for providing survey data on resource utilisation, and to Staffan Lindblad, MD (Karolinska Institute, Stockholm), for providing data on work capacity.

The study was supported with an unrestricted grant from Wyeth Research, Collegeville PA, USA.

\section{Authors' affiliations}

G Kobelt, Karolinska Institute, Stockholm, Sweden, and European Health Economics SAS, Mulhouse, France

P Lindgren, Karolinska Institute and Stockholm Health Economics, Stockholm, Sweden

A Singh, Wyeth Research, Collegeville, PA, USA

L Klareskog, Rheumatology Unit, Department of Medicine, Karolinska Institute/Hospital, Stockholm, Sweden

\section{REFERENCES}

1 Kobelt G. Health economic assessment of medical technology in chronic progressive diseases: multiple sclerosis and rheumatoid arthritis. Department of Medicine, Division of Health Economics, Stockholm: Karolinska Institute, 2003.

2 Kobelt G, Eberhardt K, Jönsson L, Jönsson B. Economic consequences of the progression of rheumatoid arthritis in Sweden. Arthritis Rheum 1999;42:347-56

3 Kobelt G, Jönsson L, Lindgren P, Young A, Eberhardt K. Modeling the progression of rheumatoid arthritis. A Two-country model to estimate costs and consequences RA. Arthritis Rheum 2002;46:2310-19.

4 Fries J, Spitz P, Kraines R, Holman H. Measurement of patient outcome in arthritis. Arthritis Rheum 1980;23:137-45.

5 Torrance G. Measurement of health state utilities for economic appraisal. A review. J Health Econom 1986;5:1-30.

6 Kobelt G, Lindgren P, Young A, Eberhardt K. Cost and effects of leflunomide in the UK. Eur J Health Econom 2002;3:173-9.

7 Kobelt G, Jönsson L, Young A, Eberhardt K. The cost-effectiveness of infliximab (Remicade(R)) in the treatment of rheumatoid arthritis in Sweden and the United Kingdom based on the ATTRACT study. Rheumatology (Oxford) 2003;42:326-35.

8 Kobelt G, Eberhardt K, Geborek P. TNF-inhibitors in the treatment of rheumatoid arthritis in clinical practice: costs and outcomes in a follow-up study of patients with RA treated with etanercept or infliximab in southern Sweden. Ann Rheum Dis 2004;63:4-10

9 Klareskog L, van der Heijde D, de Jager JP, Gough A, Kalden J, Malaise M, et al. Therapeutic effect of the combination of etanercept and methotrexate compared with each treatment alone in patients with rheumatoid arthritis: a double-blind randomised controlled trial. Lancet 2004;363:675-81.

10 Sonnenberg F, Beck J. Markov models in medical decision making. Med Decis Making 1993; 13:322-38.

11 Scott D, Pugner K, Kaarela K, Doyle DV, Woolf A, Holmes J, et al. The links between joint damage and disability in rheumatoid arthritis. Rheumatology (Oxford) 2000;39:122-32.

12 Wolfe F, Mitchell D, Sibley JT, Fries JF, Bloch DA, Williams CA, et al. The mortality of rheumatoid arthritis. Arthritis Rheum 1994;37:481-94.

13 Pincus T, Sokka T, Wolfe F. Premature mortality in patients with rheumatoid arthritis: evolving concepts. Arthritis Rheum 2001;44:1234-6.

14 Chehata J, Hassell A, Clarke S, Mattey DL, Jones MA, Jones PW, et al. Mortality in rheumatoid arthritis: relationship to single and composite measures of disease activity. Rheumatology (Oxford) 2001:40:447-52.

15 Yelin E, Turpin L, Wong B, Rush S. The impact of functional status and change in functional status on mortality over 18 years among persons with rheumatoid arthritis. J Rheumatol 2002;29:1851-7.

16 Mitchell D, Spitz P, Young D, Bloch D, McShane D, Fries J. Survival, prognosis and causes of death in rheumatoid arthritis. Arthritis Rheum 1986;29:1072-7.

17 Symmons D, Jones $M$, Scott D, Prior P. Longerm mortality outcome in patients with rheumatoid arthrits: early presenters continue to do well. J Rheumatol 1998:25:1072-7.

18 Wallberg-Jonsson S, Ohlman M, Dahlqvist S. Cardiovascular morbidity and mortality in patients with seroposivie rheumatoid arthritis in Northern Sweden. $J$ Rheumatol 1997;24:445-51.

19 Riise T, Jacobsen B, Gran J, Haga H, Arnesen E. Total mortalilty is increased in rheumatoid arthritis. A 17 year prospective study. Clin Rheumatol $2001 ; 20: 123-7$.

20 Lindqvist $\mathrm{E}$, Eberhardt K. Mortality in rheumatoid arthritis patients with disease onset in the 1980s. Ann Rheum Dis 1999:58:11-14.

21 Kroot E. No increased mortality in patients with rheumatoid arthritis: up to 10 years follow-up from disease onset. Ann Rheum Dis 2000;59:954-8.

22 DAS website. How to use the DAS, UMC Sint Radbound Nijmegen, 2004.http:// www.das-score.nl, accessed 25 February, 2005

23 Kvien T. Epidemiology and burden of illness of rheumatoid arthritis. Pharmacoeconomics 2004;22:1-12.

24 Jacobsson L, Lindroth Y, Marsal L, Tejler L. Malmömodellen för privat och offentlig reumatologisk öppenvard. Läkartidningen 2001;98:4710-16.

25 The EuroQol Group. EuroQol-a new facility for the measurement of healthrelated quality of life. Health Policy 1990;16:199-208.

26 Dolan P, Gudex C, Kind P, Williams A. A social tariff for EuroQol: results from a UK general population survey. York: Centre for Health Economics, University of York, 1995.

27 Lindblad S. Svenska RA-registret, www.reumatiker.se/tidningar/nr304/ 040350.pdf, accessed 25 February, 2005.

28 Södra Sjuksvards-Region. Price list, 2004.http://www.srvn.org/ prislista.htm, accessed 25 February, 2005

29 FASS. Läkemedel i Sverige [Pharmaceutical lexicon]. Stockholm: Läkemedelsinformation AB, 2004, (ISBN 91-85314-71-4.).

30 Statistics Sweden. Statistiska Centralbyran, 2003.www.scb.se/plubikat/sm/ arbetsmarknad.asp, accessed 25 February, 2005.

31 Lothgren $M$, Zethraeus $N$. Definition, interpretation and calculation of costeffectiveness acceptability curves. Health Econom 2000;9:623-30.

32 Fenwick E, Claxton K, Sculpher M. Representing uncertainty: the role of costeffectiveness acceptability curves. Health Econom 2001;10:779-87.

33 Efron B, Tibshirani R. An introduction to the bootstrap. London: Chapman \& Hall, 1998.

34 Bathon J, Genovese M, Martin R, et al. Etanercept (Enbrel) in early erosive rheuatoid arthritis (ERA-Trial): observations at 3 years [abstract]. Ann Rheum Dis 2002;61 (suppl I):i54.

35 Genovese M, Martin R, Fleischman R, Keystone E, Bathom J, Tsuji W. Etanercept (Enbrel) in early erosive rheumatoid arthritis (ERA-Trial): 4 year clinical and radiographic data [abstract]. Ann Rheum Dis 2003;62(suppl I): 1183 .

36 Almbrand B, Johannesson M, Sjostrand B, Malmberg K, Ryden L. Costeffectivenesss of intense insuslin treatment after acute myocardial infarction in patients with diabetes mellitus. Eur Heart J 2000;21:733-9.

37 Weinblatt ME, Genovese MC, Moreland LW, et al. Efficacy and safety of over 7 years of etanercept therapy in North American patients with early and longstanding rheumatoid arthritis [abstract]. Proceedings of ACR anvual meeting 2004.

38 NICE. Betaferon and glatiramer acetate for the treatment of multiple sclerosis. NICE Technology Appraisal Guidance No 32, 2001

39 Cutler D, Richardson E. The value of health: 1970-90. American Economic Review Papers and Proceedings, 1998; No 88. 